Motrivivência Ano XXI, No 32/33, P. 375-388 Jun-Dez./2009

\title{
TRABALHO FEMININO EM DOSE DUPLA: onde está o lazer?
}

Alessandro Barreta Garcia'

\section{Resumo Abstract}

O objetivo deste ensaio é apresentar o quadro teórico da inserção da cultura corporal de lazer entre trabalhadoras de baixa renda e baixo nível educacional, evidenciando os possíveis malefícios em função da dupla jornada de trabalho (trabalho formal e trabalho doméstico). Buscando, portanto, reproduzir a precarização do lazer a partir da falta de cultura corporal. Entendendo enfim em que medida o lazer se expressa de forma cultural e historicamente determinada.

Palavras-Chave: Lazer; Trabalho Doméstico; Dupla Jornada; Cultura Corporal.
The objective of this assay is to present the theoretical picture of the insertion of the corporal culture of leisure between low income workers and low educational level, evidencing the possible curses in function of the double hours of working (formal work and domestic work). Searching therefore, to reproduce the precarious of the leisure from the lack of corporal culture. Understanding at last where measured the leisure is express of cultural form and historically determined.

Key Words: Leisure; Domestic Work; Double Day; Corporal Culture. 


\section{Introdução}

Alguns dos estudiosos na área do lazer ${ }^{2}$ apresentam-no como um fenômeno cada vez mais abordado, tanto por sua importância em função da grande gama de possibilidades de se realizar em tempo disponível ${ }^{3}$ (MARCELLINO, 2002; CAMARGO, 1998), quanto pelo fato de proporcionar um componente artístico e cultural. DUMAZEDIER (2001) distingue as principais formas de lazer à disposição nos grandes centros urbanos, que podem ser momentos para o desenvolvimento (da cultura do corpo, da sensibilidade, da razão ou da técnica), para o divertimento (recreação e entretenimento) e para o descanso (restauração dos componentes fisiológicos). Para RUSSELL (2002), o homem deveria ter plena condição de gozar de um tempo livre ${ }^{4}$, não só para seu divertimento, mas para o aprimoramento de seus conhecimentos e de sua capacidade de reflexão.

A partir desta realidade colocamos em discussão a inserção da mulher no mercado de trabalho,
(ITABORAI, 2002). Meados da década de 70 (período em que o movimento feminista no Brasil se mostrou com maior evidência), a mulher economicamente ativa tem-se deparado com situações negativas tais como a dupla jornada de trabalho, falta de divisão de tarefas domésticas, e falta de lazer (PELICIONI, 1995; CAMPOS, 1996; MOURÃO, 1999; DE OLIVEIRA, 1999; PIRES, 2001). Ademais é relatado um alto índice de fadiga muscular, nervosismo e possíveis desequilíbrios emocionais. (MARCON e col 1997; ROCHA, 1999).

A partir destes pressupostos, nos perguntamos; a) de que forma essas barreiras podem impedir o lazer? b) qual a interferência no processo de aquisição de uma cultura corporal de lazer entre mulheres que trabalham? Por acreditar que a mulher assume um papel cada vez mais complexo na sociedade. Em virtude da jornada dupla de trabalho, dos deveres domésticos e das funções relacionadas ao cuidado com os filhos e do marido, aliado ao fato de estarem se dedicando ao trabalho,

2 Segundo Dumazedier (2001), "O lazer é um conjunto de ocupações às quais o indivíduo pode entregar-se de livre vontade, seja para repousar, seja para divertir-se, recrear-se e entreter-se ou, ainda para desenvolver sua informação ou formação desinteressada, sua participação social voluntária ou sua livre capacidade criadora após livrar-se ou desembaraçar-se das obrigações profissionais, familiares e sociais". (34p, 2001).

3 Marcellino (2002) concorda que não existe tempo livre para representações sociais, neste sentido utiliza o termo tempo disponível.

4 Apesar de adotarmos o termo tempo disponível, o termo tempo livre e usado quando for referido a autores que o adotam. 
Ano XXI, n 32/33, junho e dezembro/2009

é que vislumbramos um enfoque no estudo do lazer feminino.

AQUINO e col (1991)

ressaltam esta preocupação em um levantamento da mortalidade feminina, levantando a possibilidade de novos agravamentos à saúde feminina e uma possível equiparação das causas de morte a fatores que incluem uma maior inserção da mulher no mercado de trabalho.

Neste sentido o objetivo deste ensaio é; a) reunir estudos nacionais (referente a realidade brasileira) pelos quais apresentam atividades realizadas entre mulheres economicamente ativas, (de baixa renda e baixo nível educacional), sendo o lazer requisito de inclusão como delimitação do objeto de nosso estudo; b) direcionar este ensaio a partir dos pressupostos que sustentam o lazer como cultura corporal.

\section{Considerações sobre a cultura corporal de movimento}

Dentro de uma perspectiva Antropológica, vamos nos concentrar em alguns fundamentos teóricos que servem de base para o entendimento das atividades de lazer, como cultura corporal. De acordo com Clinford Geertz, é a partir dos Australopithecus que possuíam um cérebro cerca de $1 / 3$ menor que o do ser humano moderno, e que provavelmente possuíam traços de uma semicultura (manufaturavam objetos e caçavam pequenos animais) é que iremos nos fundamentar de forma específica.

Apesar de não existir evidência na qual se tenha reconhecido algum tipo de linguagem é possível entender que o aumento do cérebro se deu posteriormente ao início de uma cultura rudimentar, (DE LIMA, 1990; LARAIA, 2003). A manipulação de objetos a manufatura de ferramentas e prováveis caçadas a pequenos animais realmente ocorreram, e provavelmente deu-se continuidade a espécie humana em virtude de uma cultura subestruturada mas já presente entre os nossos mais remotos ancestrais. Neste sentido a evolução deste enquanto ser social não tem sido aceita somente a partir do aumento quantitativo no número de neurônios, mas acima de tudo por sua relação social, psicológica e cultural.

Segundo GEERTZ (1989), "Se a existência de um tipo moderno de mente é considerada pré-requisito para a aquisição da cultura, a posse universal da cultura por parte de todos os grupos humanos contemporâneos faz com que a doutrina da unidade psíquica seja uma simples tautologia" (75p, 1989). Esta doutrina afirma não haver diferenças na natureza humana quanto ao processo de pensamento 
entre varias raças (GEERTZ, 1989). Lévi-Strauss reformula a teoria dizendo que o pensamento esta arraigada em regras inconscientes, sendo princípios norteadores da mente e de certa forma controladores de agrupamentos sociais (LARAIA, 2003).

Para GEERTZ (1989), “Um ser humano sem cultura seria, provavelmente, não um macaco intrinsecamente talentoso, embora incompleto, mas apenas uma monstruosidade totalmente sem mente e, em conseqüência, sem possibilidade de ser trabalhada" (81p, 1989). GEERTZ (1989, p92) ainda explica,

"O intelecto humano, no sentido específico do raciocínio orientador, depende da manipulação de certos tipos de recursos culturais, de maneira tal produzir (descobrir, selecionar) os estímulos ambientais necessários para o organismo - qualquer que seja o propósito; trata-se de uma busca de informação".

Esta cultura aqui assumida, e presente em nossas representações sociais são o fato que mais nos interessa no momento, seja em função dos movimentos físicos culturalmente repassados, seja nos movimentos do cotidiano nos quais estão explícitos tanto em nossa história de vida como nas atitudes, valores e nos nossos repertórios advindos dos nossos antecedentes. Langer citado por GEERTZ (1989) acrescenta, "em virtude de nosso pensamento e de nossa imaginação, dispomos não apenas de sentimentos, mas de uma vida de sentimentos" (95p, 1989). Acreditamos em fim em uma cultura corporal por parte de uma série de sentimentos, sentidos e valores. Esta cultura corporal se expressa em atitudes, em linguagens seja ela corporal ou não. O mundo externo e as nossas atitudes nos influenciam em função de nossa própria vida passada, aquela que será constantemente lembrada e repensada. Neste sentido GEERTZ (1989), descreve,

"Para tomar nossas decisões, precisamos saber como nos sentimos a respeito das coisas; para sabermos como nos sentimos a respeito das coisas precisamos de imagens públicas de sentimentos que apenas o ritual, o mito e a arte podem fornecer" (96p, 1989).

Entendemos o mesmo acerca da cultura corporal, é preciso saber algo sobre nossas imagens corporais, tanto nosso ritual para com nossas experiências na, dança ou na prática esportiva de lazer, ou seja, em qualquer outra atividade, 
Ano XXI, n 32/33, junho e dezembro/2009

precisa-se mais que condição precisa-se de imagens, de linguagem, formas e expressões.

Essencialmente falando do homem moderno quanto sua evolução, tanto ferramentas, caça e suas organizações familiares foram extremamente necessárias para a sobrevivência tanto quanto para sua própria existência GEERTZ (1989). A cultura corporal neste sentido de essencialidade é também necessária para o desenvolvimento físico, cultural, e popularmente aceito por todas as sociedades.

A exemplo MAUSS (1974), cita, "a criança acocora-se normalmente" "Nós não sabemos acocorar" "Considero isso um absurdo e uma inferioridade de nossas raças, civilizações, sociedades" "as técnicas corporais são, pois as normas do treinamento humano" (220p, 1974). Neste sentido inúmeras civilizações se portam de maneira diferenciada, as tropas marcham de maneira diferenciada, nadam de maneira diferenciada, ou seja, possuem técnicas diferenciadas (MAUSS, 1974).

No seu exposto o autor deixa clara a educação, imitação nas quais desencadeiam em uma série de linguagens corporais diferenciadas no que chamará de movimento não natural (neste sentido, coloca o movimento técnico opondo-se ao movimento livre e sem descrições rígidas). Este autor ainda classificará como ato tradicional, principalmente diferenciado em função do sexo da idade ou classe. Segundo MAUSS (1974) pode-se treinar, para alcançar ótimo rendimento, tornando o movimento mecânico e artificial.

MAUSS (1974) contribui imensamente para com as questões culturais, suas observações são de grande valia para os estudiosos da cultura corporal, pois trazem a luz sérios desdobramentos, para a educação do movimento e suas implicações quanto à formação do cidadão (separando esta em atos naturais e não naturais).

Ademais o que mais nos interessa neste momento é entender a cultura corporal como uma série de movimentos específicos ou não, passados entre gerações de forma consciente e inconscientemente pertencente ao convívio social, psicológico e cultural. Entendemos a cultura corporal em função das atividades corporais, subsidiadas a partir da educação cultural, da expressão e manifestação desta através de sua prática cotidiana livre de repressões (opondo-se ao movimento artificial, ou não natural).

Sendo estas atividades, o esporte, algum tipo de atividade em academia de ginástica, algum tipo de dança, atividade terapêutica (relaxamento), luta, caminhada em ruas, parques, praças ou outras atividades corporais que se 
enquadrem na naturalidade, no divertimento e na relação humana espontânea (GONÇALVES JÚNIOR, 2003). Consideramos este convívio humano de extrema importância tanto para o desenvolvimento da atividade em si, como para o distanciamento das responsabilidades diárias com o trabalho (o lazer propriamente dito).

\section{Lazer e trabalho}

Ao iniciarmos nossa trajetória o primeiro trabalho a ser apresentado nesta pesquisa refere-se a PELICIONI (1995). Esta autora objetivou em seu trabalho, conhecer as condições de vida e as atitudes expressas no cotidiano de mulheres trabalhadoras. Foi estudada uma população de 154 mulheres (entre 18 e 61 anos de idade) trabalhadoras, em sete creches conveniadas com a Prefeitura Municipal de São Paulo, que participaram de uma entrevista devidamente testada pela autora. Os principais resultados encontrados na pesquisa, em termos de opções de lazer, são os seguintes: de segunda a sexta escutar radio $80,5 \%$, ler revistas 53,3\%, assistir TV 48,7\%, ler livros $45,5 \%$ e $7,1 \%$ para leitura de jornais; aos sábados os resultados não são muito diferentes e são acompanhados de serviços domésticos e compras para casa com $94,1 \%$ aos sábados e 68,8\% aos domingos; cerca de 1,3\% praticam esporte aos sábados. A referida autora constatou também que $70 \%$ das informantes têm filhos, 66,4\% são menores e dependentes e $46,7 \%$ das trabaIhadoras são chefes de família. Podemos concluir por esse trabalho, que são praticamente inexistentes as atividades de lazer em relação ao desenvolvimento da expressão e cultura corporal do grupo estudado, sendo as únicas formas de lazer dessas trabalhadoras o ato de escutar radio e assistir TV.

No estudo apresentado por CAMPOS (1996) também são ressaltados os elementos envolvidos nas práticas cotidianas das mulheres, verificando em que medida sua condição determinava e comprometia seu tempo de lazer. O estudo se realizou a partir de entrevistas com 30 operarias de uma indústria de calçados na cidade de Franca, as quais tinham idade entre 25 e 35 anos, eram casadas e tinham filhos com menos de dez anos de idade. Após um consenso percebido pela autora, tendo em vista sua revisão conceitual, tratou-se o lazer como toda atividade livre de trabalho que não está acompanhada de obrigações. É importante ressaltar que esse consenso tem sido apresentado por uma série de estudos, tais como CAMARGO (1998); DUMAZEDIER (2001); MARCELLINO (2002). Pela análise dos resultados da pesquisa, 
Ano XXI, n 32/33, junho e dezembro/2009

foi constatado que praticamente todas essas mulheres/operárias assumiam sozinhas o papel de responsáveis pelos fazeres domésticos. Nesse sentido, os principais exemplos ficam por conta de lavar roupa, passar o uniforme escolar dos filhos, fazer o jantar, organizar a casa, orientar a lição dos filhos, entre outras coisas.

Basicamente, o único tempo destinado ao lazer encontra-se nos finais de semana, quando a família se reúne. De acordo com CAMPOS (1996), notamos que existe a possibilidade de haver diferenças entre as idades e entre os graus de escolarização. Nota-se que as mais jovens e mais escolarizadas podem ter mais tempo dedicado ao lazer e serem mais críticas com relação à divisão das atribuições entre toda a família. Concluindo, CAMPOS (1996) destaca que o aspecto mais evidente é que essas mulheres/operarias praticamente só dispõem de horas de sono para recuperar-se da fadiga; fica claro que para elas é muito difícil conseguir realizar alguma atividade de lazer. Neste caso, uma maior compreensão da família, em especial do marido e dos filhos poderia contribuir para ampliar as atividades de lazer, aparentemente pouco existentes na vida destas mulheres.

Para MOURÃO (1999), em sua análise da representação social da relação do trabalho e das opções de lazer de diaristas (faxineiras) do município de Queimados, a situação não é diferente. A autora identifica uma série de inquietações que o investigador deve ter ao pesquisar essa relação. Seu foco de interesse foi identificar as rotinas diárias dessas mulheres, com quem ficavam os filhos, qual era o tempo destinado ao lazer. A partir de um roteiro de perguntas, as informantes, num total de dez mulheres com idade entre 23 e 46 anos, oito solteiras, uma divorciada e uma separada, todas com no mínimo um filho e no máximo cinco filhos, saem de casa por volta das 4 horas da manhã e são expostas a no mínimo três horas de condução até chegar ao serviço. Ao chegar em casa, por volta das dez horas da noite, essas mulheres ainda executam uma série de atribuições, como cuidar da casa, dos filhos, fazer o jantar ensinar o dever de casa etc. Em relação ao tempo de descanso dessas mulheres detectou-se em média cinco horas por noite.

MOURÃO (1999) destaca que as diaristas (faxineiras) entrevistadas apresentam uma série de impedimentos para usufruir algumas horas de lazer (falta de tempo, problemas financeiros etc), essas mulheres ainda deixaram claro certa confusão no próprio entendimento sobre a diferenciação do que é lazer e o que é função materna. De 
acordo com as dificuldades da muIher que trabalha a falta de tempo e dinheiro, fato esse que somado à jornada dupla de trabalho e à submissão feminina aos papéis de mãe e esposa repercute seriamente sobre a possibilidade de realizar atividades de lazer (PELICIONI, 1995; CAMPOS, 1996; MOURÃO, 1999; De Oliveira, 1999; PIRES, 2001). Por ocasião desta realidade, é possível entendermos a dupla jornada de trabalho (público e privado) feminino como um possível fator de deterioração da auto-estima, causador de depressão, cansaço fisco e profundo estimulador do esgotamento físico e mental. O trabalho feminino (público e privado) aqui caracterizado como possivelmente prejudicial, lembra-nos o trabalho fabril no início do processo capitalista (séc XVII e XVIII).

ROCHA (1999), estudando enfermeiras no campo de trabalho, teve como objetivo identificar aspectos da vida diária dessas profissionais, bem como os fatores de risco para provocar lombalgias. Apesar desse estudo não ter o objetivo específico de levantar as representações de lazer da mulher, e da amostra incluir um número pequeno de homens $(17,1 \%)$, que poderiam confundir nossa interpretação, esse trabalho dá a sua contribuição para a constatação da dificuldade encontrada por mulheres frente às jornadas de trabalho, e da inexistência de algum tipo de lazer para a maioria dessas trabalhadoras.

Trata-se de um estudo descritivo, com entrevistas seguindo um roteiro com questões abertas e fechadas, em uma amostra de 76 profissionais de enfermagem, sendo $82,9 \%$ dos entrevistados do sexo feminino, com idade média de 32 anos. Em relação à variável de lazer, detectou-se que $51,5 \%$ dos entrevistados mencionaram a prática de exercícios físicos de forma regular, sendo a atividade física a mais citada. Por outro lado, cerca de 55,3\% alegaram não fazer nenhum tipo de atividade física ou exercício físico. Em outra variável de nosso interesse, cerca de $53,9 \%$ das informantes relataram fazer algum tipo de serviço doméstico, tal como lavar roupa manualmente, faxina geral etc. Em relação à variável número de filhos, cerca de $60,5 \%$ dos entrevistados não tinham filhos, 15,8\% tinham apenas um filho, $14,5 \%$ tinham dois filhos e 9,2\% tinham de três a cinco filhos, (ROCHA, 1999).

As mulheres investigadas nos estudos de PELICIONI, (1995); CAMPOS, (1996); MOURÃO, (1999); ROCHA, (1999), apesar de alguns deles terem objetivos e metodologias diferenciadas, parecem chegar ao seguinte consenso: demonstram que a vida dessas mulheres trabalhadoras após o ca- 
Ano XXI, n 32/33, junho e dezembro/2009

samento tornou-se mais complicada em função do acúmulo de trabalhos domésticos e preocupações financeiras, itens possivelmente determinantes para a impossibilidade de usufruir seu relativo tempo disponível para o desenvolvimento do lazer. Já o cansaço após o trabalho é um fator importante, pois estão esgotadas e ainda assim seguem sua dupla jornada até concluir grande parte de suas atividades familiares.

Além dessas questões, fica claro a homogeneidade dos grupos, que, de um lado demonstra que muIheres de baixa renda sofrem diversas restrições para a prática de lazer e, de outro, abre-se certa lacuna em relação ao que poderiam representar amostras diferenciadas nas variáveis: idade, nível econômico, nível de escolaridade e diferentes funções no mercado de trabalho. Porém não se pode considerar a mulher como um grupo homogêneo, mas sim diferenciado por uma série de questões dentro de um contexto histórico econômico e social.

\section{Dupla jornada e seus male- fícios}

Levantadas no capitulo anterior as atividades de lazer além de praticamente não existirem entre mulheres economicamente ativas de baixa renda e baixo nível educacional, também parecem ser um desejo inatingível, em razão de toda a dinâmica da dupla jornada de trabalho, já levantada nesta revisão. Além da repercussão da dupla jornada de trabalho, impossibilitando essa mulher economicamente ativa de participar de atividades de lazer, também salientaremos agora os efeitos deletérios para com sua saúde ${ }^{5}$.

Nesse sentido, salientamos que é cada vez mais crescente o número de mulheres no mercado de trabalho. Muitas são as responsabilidades dessas mulheres para com suas famílias, para com as finanças de suas famílias, tornando-as chefes de seus lares, aumentando seu sofrimento, seu desgaste físico, muitas vezes com uma distribuição de tarefas quase desumana, (MOTTA \& NETO, 1985; ROCHA, 1999; MEDEIROS \& MARTINS, 2002). MEDEIROS \& MARTINS (2002), entrevistaram mulheres (64 entre as 542) registradas em prontuários do serviço de saúde mental da Cidade de São Carlos, São Paulo. As entrevistadas relacionaram a sua história de vida (também referente a trabalho) com as possíveis causas do

5 Com base em Dejours, Dessors, \& Desriaux (1993) assume-se o entendimento de saúde, conforme suas palavras, "saúde não é um estado, mas um objetivo que se remaneja sem cessar", "não é alguma coisa que se tem ou não se tem, mas que se tenta conquistar e que se defende, como a liberdade" (104.p, 1993). 
adoecimento, confirmado no prontuário médico. $O$ trabalho doméstico seguido do trabalho remunerado na indústria foram as predominantes no grupo economicamente ativo, mas também existiam mulheres que exerciam estritamente o trabalho doméstico não remunerado. Os principais resultados da pesquisa demonstram que tanto as que trabalham fora como as que trabalham em sua residência, sofrem praticamente os mesmos problemas. A sobrecarga no trabalho, cansaço, crises no casamento, falta de tempo e o fato de não ter com quem dividir as tarefas domésticas foram as mais preocupantes. Em relação ao adoecimento, é atribuído à fraqueza pessoal, a uma falha de sua própria natureza, sentimento de solidão transformando-se em depressão e autodepreciação.

ROCHA (1999) entrevistou 76 trabalhadores de enfermagem, sendo $82,9 \%$ dos participantes do sexo feminino com idade média de 32 anos participantes do mercado de trabalho, assumindo elevada carga de trabalho em função da dupla jornada. Os problemas apontados ficam por conta de distúrbios osteomusculares apresentados como decorrentes de esforço físico excessivo. Sendo assim, a falta de lazer somada à dupla jornada de trabalho (referente a precária na divisão de funções) poderiam refletir um quadro péssimo para à saúde feminina.

No estudo de MARCON \& KOGA e col (1997), cuja amostra se caracterizou por 151 mulheres, $64 \%$ casadas, $57 \%$ com casa própria, $50 \%$ recebendo 5 salários mínimos e $47 \%$ possuindo terceiro grau completo. Os resultados apresentados de forma quantitativa apontam a existência de um equilíbrio nas atividades de lazer, atividades pessoais e atividades para com os filhos. Quanto às funções domésticas, porém, embora parte das mulheres possuísse empregada, predominou o fato de serem mulheres no sentido privado ${ }^{6}$. Em razão de o estudo ter sido focado em servidoras, boa parte destas com terceiro grau completo, os resultados expostos de forma quantitativa podem não demonstrar a totalidade da problemática em questão.

No estudo de AQUINO \& ARAUJO e col (1993), representado por enfermeiras $(n=94)$ e auxiliares de enfermagem $(n=397)$, nota-se que ambos os grupos são caracterizados por extensas cargas de trabalho. A

6 Privado no sentido doméstico da interioridade e da instintividade (feminina). Já o público refere-se à força, inteligência e capacidade de decisão (masculina). Pertinente a caracterização dos espaços do feminino e do masculino segundo Meis, citado por Rocha \& Martins (2002). 
Ano XXI, n 32/33, junho e dezembro/2009

primeira diferença fica por conta dos esforços físicos considerados mais pesados no grupo de auxiliares de enfermagem quando comparado com as enfermeiras. Uma provável explicação reside na própria característica das chamadas nurses (auxiliares) diferindo-se das ladies nurses (enfermeiras supervisoras) Almeida \& Rocha, citado por AQUINO \& ARAUJO e col (1993), em função da divisão do trabalho que se caracteriza por uma maior carga física exercida pelo trabalho de característica mais física e menos burocrática.

Quanto ao trabalho doméstico, as enfermeiras têm em média 13,9 horas semanais, enquanto as auxiliares de enfermagem em torno de 24,2 horas. Nesse sentido, salienta-se a presença de diaristas e empregadas domésticas em relação às enfermeiras (supervisora). De acordo com o quadro de saúde, as auxiliares apresentam as piores condições, com altíssima prevalência de obesidade (16\%) e sobrepeso $(42 \%)$, comparadas com as enfermeiras (supervisoras) 5\% e 16\%, respectivamente. Com relação aos problemas crônicos, a freqüência se mostra homogênea pela ocorrência de varizes, pressão alta, problemas digestivos e alérgicos. Embora se tais complicações na saúde das enfermeiras e auxiliares de enfermagem se observem em ambos os grupos, é alarmante a maior incidência no grupo das auxiliares, em função de dores na coluna, pressão arterial alta e varizes. Finalmente, acreditase que os trabalhos domésticos, somados ao trabalho formal, podem contribuir para o aparecimento de fadiga crônica, desgaste físico, além de patologias específicas (AQUINO \& ARAUJO e col, 1993).

AQUINO \& MENEZES e col (1991), já haviam levantado essa preocupação. Segundo Verbrugge, além de doenças eminentes como as cerebrovasculares, pulmonares entre outras, tem se destacado a grande participação das mulheres como chefes de família, com maior organização política e ingresso no mercado de trabalho. Nesse sentido ressaltam-se as atribuições no âmbito doméstico, pelo fato de cuidarem dos filhos, do lar, ficando clara a nítida caracterização de seu papel como chefes de família e sua participação nos gastos familiares, (CORREIA, 1997; ROCHA \& DEBERT-RIBEIRO, 2001), entre outras preocupações.

Entendemos que as medidas a serem tomadas, não devem ser apenas as políticas públicas, educacionais, de cultura ou de lazer. Acreditamos que o empenho do gênero feminino é tão importante quanto as variáveis acima. No sentido de buscar melhores condições de trabalho, melhor remuneração, maior nível educacional e maior liberdade de expressão, é preciso 
pensar alternativas, tanto no meio acadêmico, no âmbito individual da ação da mulher na sociedade. No entanto deve-se ter a noção que um excesso de trabalho formal e não formal possam estar ligados a quadros não desejáveis, tais como esgotamento físico e doenças específicas.

\section{Considerações finais}

A partir deste ensaio foi possível expor uma grande falta de atividade física entre mulheres de baixa renda e baixo nível de escolaridade. Demonstramos que além de pouca ou nenhuma atividade corporal (que entendemos ser uma cultura corporal de lazer) para o desenvolvimento físico, essas trabalhadoras ainda carregam consigo a amarga tarefa de trabalhos domésticos (dupla jornada de trabalho) em praticamente todos os estudos analisados.

Inferimos que para uma cultura corporal de lazer, é necessária política educacional de saúde, tanto na infância como na adolescência. Porém não se deve executar a prática do exercício físico, simplesmente pela prática, mas acima de tudo entender sua importância histórica, cultural, social e educacional. Sendo esta uma prática socialmente determinada por uma cultura corporal mediante políticas do Estado, assume-se que esta deve ser encarada como um problema de saúde pública e um problema de para com educadores físicos.

Neste sentido uma visão mais crítica a este respeito só é visível entre mulheres com maior nível econômico e maior nível educacional. Pressupõe-se que os resultados, em termos de dupla jornada de trabalho e cultura corporal, poderão ser alterados à medida que houver maior nível econômico e educacional. Permitindo uma maior compreensão dos direitos para com a liberdade e para com a melhora na condição de vida entre mulheres que trabalham (LADEIRA, 2000). Enfim, para que a cultura corporal se estabeleça entre as mulheres em condições econômicas desfavoráveis, e um nível educacional pouco expressivo, é necessário que ocorram intervenções educacionais do Estado (no sentido de fornecer os subsídios fundamentais para com os cidadãos de sua cidade) no sentido de permitir uma inserção satisfatória, e acima de tudo com total liberdade para desenvolver uma cultura corporal de lazer a seu gosto.

\section{REFERÊNCIAS}

AQUINO, E. M. L, MENEZES, G. M, AMOEDO, M. B. E, et al. Mortalidade feminina no Brasil: Sexo frágil ou sexo forte. 
Ano XXI, n 32/33, junho e dezembro/2009

Cadernos de Saúde Pública, 7 (2) 174- 189p, 1991.

CAMARGO, L. O. L. Educação para o lazer. São Paulo, Editora Moderna, 1998, 160p.

CAMPOS, R, A. O lazer da mulher no contexto profissional e familiar: Uma investigação com mães operárias da industria calçadista da cidade de Franca. Dissertação de Mestrado em Serviço Social - Faculdade de História Direito e Serviço Social, Universidade Estadual Paulista Júlio de Mesquita Filho, 1996, 89p.

CORREIA, G. B. Sexualidade e Maternidade: "nós" e "laços" de um fenômeno cultural. Revista Brasileira de Sexualidade Humana, v. 8, n.1, p. 21-34, 1997.

COSTA, I. T. M. Informação, trabalho e tempo livre: Políticas de informação para o século XXI. Ciência da Informação, v.28, n.2, p.136-138, 1999.

DA MOTTA, A. B, NETTO, Z.M. Tempo de mulher - tempo de trabalho entre mulheres proletárias em Salvador. Ciência e Cultura, v. 37, n. 9, p. 14421451, 1985.

DE LIMA, C. P. Evolução Humana. Editora Ática, 1990, 95.p.

DE OLIVEIRA, S. R. A relação das mulheres que fazem parte da população economicamente ativa, casadas, que tem filhos, com o lazer. Revista Brasileira de Ciências do Esporte, v. 21, n. 1, p. 1552, 1999.

DEJOURS, C, DESSORS, D, DESRIAUX, F. Por um trabalho, fator de equilíbrio. Revista de Administração de Empresas, v. 33, n. 3, p. 98-104, 1993.

DUMAZEDIER, J. Lazer e cultura popular. Perspectiva, 2001, $334 p$.

FISCHER, I. R. A participação da mulher no orçamento familiar. XIII ENCONTRO DA ASSOCIAÇÃO BRASILEIRA DE ESTUDOSPOPULACIONAIS, Ouro Preto, Minas Gerais de 4 a 8 de novembro de 2002 .

GEERTZ, C. A interpretação das culturas. Guanabara Koogam Rio de Janeiro, 1989, 323p.

GONÇALVES JÚNIOR, L. Cultura corporal: Alguns subsídios para sua compreensãona conteporaneidade. Instituto Superior de Estudos Interculturais e Transdisciplinares, Unidade de Investigação em Antropologia, 2003, 35p.

ILARE, R, GERALDI, J. W. Semântica. São Paulo, Editora Ática, 10 edição, 2001, 96p.

ITABORAI, N. R. Trabalho feminino e mudanças na família no Brasil (1984-1996): Comparações por classe. XIII ENCONTRO DA ASSOCIAÇÃO BRASILEIRA DE ESTUDOS POPULACIONAIS, Ouro Preto, Minas Gerais de 4 a 8 de novembro de 2002 . 
LADEIRA, K. F. Dupla jornada da mulher e qualidade de vida: A influencia do nível socioeconômico nas estratégias de conciliação entre o tempo laboral e o tempo familiar. Magister Scientiae em Economia Doméstica - Universidade Federal de Viçosa, Minas Gerais, 2000, 91p.

LARAIA, R. DE B. Cultura: Um conceito antropológico. Jorge Zahar - Rio de Janeiro, 2003, 117p.

MARCELLINO, N. C. Estudos do lazer: Uma introdução. Autores Associados, 2002.

MARCON, S. S, KOGA, M, WAIDMAN, M, A. P, et al. O trabalho da mulher: $O$ confronto com a realidade familiar. Texto e Contexto Enfermagem, Florianopolis, v.6, n.1, p. 135156, 1997.

MAUSS, M. As técnicas corporais. In. Sociologia e Antropologia. São Paulo, EPU/EDUSP, 1974. MEDEIROS, M. H. R, MARTINS, G.

O sofrimento mental feminino e sua relação com o trabalho doméstico na cidade de São Carlos (SP). Jornal Brasileiro de Psiquiatria, v. 51, n.4, p. 247258, 2002.

MONTALO, L, LOPES, G. Relações familiares e trabalho feminino na região metropolitana de São Paulo na década de 90. XIII ENCONTRO DA ASSOCIAÇÃO BRASILEIRA DE ESTUDOS
POPULACIONAIS, Ouro Preto, Minas Gerais de 4 a 8 de novembro de 2002.

MOURÃO, L. Representação social da relação do trabalho feminino da diarista com as opções de lazer na comunidade de queimados. Motus Corporis, Rio de Janeiro, v. 6, n. 2, p. 52-72, nov, 1999.

PELICIONI, M. C. F. Qualidade de vida das mulheres trabalhadoras das creches do bairro Bela Vista do Município de São Paulo. Tese de Doutorado - Faculdade de Saúde Pública da Universidade de São Paulo, 1995.

PIRES, A. G. M. G. As vozes do algodão: Bóias-frias e suas representações sociais de tempo livre e lazer. In (Org) VOTRE, S. Imaginário e representações sociais em educação física, esporte e lazer. Rio de Janeiro - Editora Gama Filho, 2001, 344p.

ROCHA, A. M. Fatores que influenciam a saúde da mulher que trabalha em enfermagem. O Mundo da Saúde, São Paulo, ano. 23, v. 23, n. 2, 1999.

ROCHA, L. E, DEBERT-RIBEIRO, $M$. Trabalho, saúde e gênero: estudo comparativo sobre analistas de sistemas. Revista de Saúde Pública, v. 35, n. 6, p. 539-47, 2001.

Recebido: Abril/2010 Aprovado: Agosto/2010 